\title{
Effect of Lymphokine-activated Killer Cells with or without Radiation Therapy against Malignant Brain Tumors
}

\author{
Kunio NAKAGAwA, Takao KamezAKI, Yasushi Shibata, \\ Takashi TSUNODA, Kotoo MEGURO, and Tadao NOSE \\ Department of Neurological Surgery, Institute of Clinical Medicine, University of Tsukuba, \\ Tsukuba, Ibaraki
}

\begin{abstract}
The use of autologous lymphokine-activated killer ( $\mathrm{LAK}$ ) cells to treat malignant brain tumors was evaluated in 10 patients, one with metastatic malignant melanoma and nine with malignant glioma. LAK cells were obtained by culturing autologous peripheral blood lymphocytes with human recombinant interleukin-2 (rIL-2) for 7-28 days. All patients underwent surgery to remove as much tumor as possible and an Ommaya reservoir was implaced in the tumor cavity. Two of the 10 patients had received radiotherapy elsewhere, so were treated with LAK cells alone. Eight patients were treated with a combination of LAK cells and radiotherapy, using 1.8-2.0 Gy fractions given five times a week with a total dosage between 54 and 65 Gy. LAK cells and rIL-2 were injected to the tumor cavity via the Ommaya reservoir once a week for inpatients and once a month for outpatients. The duration of the LAK therapy ranged from 3 to 23 months (mean 13.7 mos). Neuroimaging evaluation revealed two complete responses, three partial responses, four no changes, and one progressive disease. In one patient with pontine glioma, the Karnofsky performance score was raised from 20 to 60 . There were no side effects after the injection of LAK cells and rIL-2. The results suggest low-dose LAK therapy is a useful and safe treatment modality for malignant brain tumors.
\end{abstract}

Key words: interleukin-2, lymphokine-activated killer cells, malignant brain tumor, radiotherapy

\section{Introduction}

Surgical therapy, radiotherapy, and chemotherapy are used to treat malignant brain tumors, but are limited by the associated physical and chemical damage to the normal tissues. Immunological treatments are under intensive research because they are tumor-specific and harmless to normal tissue. Lymphokine-activated killer (LAK) cells are a potential agent obtained by culturing lymphocytes with interleukin-2 (IL-2) ${ }^{6}{ }^{6}$ However, the clinical results are controversial, with some workers concluding that immunotherapy with LAK cells would be ineffective for malignant brain tumor, ${ }^{3,17}$ while others have suggested the method is efficient and safe for patients with brain tumor. ${ }^{11,18)}$ In these studies, no cases of cure have been presented and the ratio of cases with

Received February 2, 1994;

Accepted July 7, 1994 remission is relatively low.

LAK cells can also be induced from the peripheral blood lymphocytes (PBL) of the tumor-bearing host, and the activity persists in patients with glioma $a^{4)}$ and healthy subjects. LAK cells are widely accepted to be broad-spectrum, easily induced, and harmless to normal tissues. Many clinical trials have evaluated the use of autologous LAK cells against malignant tumors. ${ }^{3,10,11,17,18)}$ Recently, several trials have attempted to improve the activity of LAK cells using the specific targeting technique or plastic adherent LAK cells. The specific targeting technique involves introducing two antibodies, the anti-CD3 and antiglioma monoclonal antibodies, into the LAK cell to intensify the binding activity to the target tumor cell. ${ }^{15)}$ The preliminary results suggest a longer survival time for the patients than in normal LAK therapy. A culture supernatant of plastic adherent LAK cells can also enhance the lytic activity of LAK cells in the 
Table 1 Patient data

\begin{tabular}{|c|c|c|c|c|c|c|}
\hline Case No. & Age/Sex & Histology & Location & Previous treatment & Tumor removal & KPS \\
\hline 1 & $47 / \mathrm{M}$ & malignant melanoma & It F-T & - & partial & 60 \\
\hline 2 & $41 / M$ & astrocytoma III & lt $\mathrm{P}$ & - & partial & 90 \\
\hline 3 & $63 / \mathrm{F}$ & glioblastoma multiforme & lt $\mathrm{F}-\mathrm{T}$ & $\mathrm{Op}+\mathrm{RT}$ & partial & 30 \\
\hline 4 & $29 / \mathrm{M}$ & astrocytoma III & $\mathrm{rt} \mathrm{P}$ & - & partial & 60 \\
\hline 5 & $40 / F$ & astrocytoma III & rt F & Op & - & 90 \\
\hline 6 & $25 / \mathrm{F}$ & astrocytoma III & pons & $\mathrm{Op}+\mathrm{RT}+$ chemo & - & 20 \\
\hline 7 & $67 / \mathrm{F}$ & astrocytoma III & rt F-T & chemo & partial & 90 \\
\hline 8 & $70 / \mathrm{F}$ & astrocytoma III & It $F-T$ & - & partial & 90 \\
\hline 9 & $38 / \mathrm{F}$ & astrocytoma III & rt F & - & subtotal & 90 \\
\hline 10 & $72 / F$ & astrocytoma III & It $\mathbf{F}-\mathbf{T}$ & - & partial & 40 \\
\hline
\end{tabular}

chemo: chemotherapy, F: frontal lobe, KPS: Karnofsky performance score, Op: surgery, P: parietal lobe, RT: radiation therapy, T: temporal lobe.

glioma system of rats. ${ }^{16)}$

The cytotoxic mechanism of LAK cells is thought to be recognition of the antigenic determinants of tumor cells ${ }^{\text {9) }}$ followed by production of cytotoxic factors. ${ }^{7)}$ Our previous animal experiments revealed that 5 Gy of irradiation enhanced the natural killer (NK) or LAK cell activity, ${ }^{13,14)}$ due to an increase in the release of cytotoxic factors from LAK cells or NK cells following irradiation.

In this study, 10 patients with malignant brain tumors were treated with a combination of LAK cells and irradiation, or LAK cells alone, and evaluated by computed tomography (CT) or magnetic resonance (MR) imaging, and the neurological status including the Karnofsky performance score.

\section{Materials and Methods}

Ten patients, one with metastatic malignant melanoma and nine with malignant astrocytoma, were treated with a combination of LAK cells and irradiation ( 8 patients) or LAK cells alone ( 2 patients) (Table 1). Informed consent was obtained from all patients or guardians.

PBL were isolated from $100 \mathrm{ml}$ of heparinized blood from each patient by a standard Ficoll-Conray density-gradient centrifugation technique. After centrifugation, the red blood cells were returned to the patient. PBL were suspended in RPMI 1640 (Nissui Co., Tokyo) at $1 \times 10^{6} / \mathrm{ml}$ supplemented with $1-2 \%$ human $\mathrm{AB}$ serum and $1000 \mathrm{U} / \mathrm{ml}$ recombinant human IL-2 (rIL-2) (Shionogi Co., Ltd., Osaka) and incubated for 7-28 days. 1-10 × $10^{7}$ LAK cells were resuspended in $0.5 \mathrm{ml}$ of Hanks' balanced salt solution (HBSS) (Whittaker Bioproduct, Walkersville, Md., U.S.A.) supplemented with $1 \times 10^{4} \mathrm{U} / \mathrm{ml}$ of rIL-2.
The tumor was treated surgically in eight patients. A catheter was placed in the postoperative cavity connected with an Ommaya reservoir (Baxter Healthcare Co., Deerfield, IIl., U.S.A.) placed beneath the galea. Only one patient (Case 5 ) received surgery to implace the Ommaya reservoir without tumor removal because the recurrent tumor had seeded to the ventricular system. Case 6 was not treated because she had received surgery before. Conventional ionizing radiotherapy (1.8-2 Gy per fraction, five times a week) was given to eight patients, with total radiation doses ranging from 54 to $65 \mathrm{~Gy}$. Eight of the 10 patients received a local injection of LAK cells and rIL-2 via the Ommaya reservoir once a week during radiotherapy. The other two patients (Cases 3 and 6) were treated with LAK cells alone via the Ommaya reservoir because they had previously received irradiation at another hospital.

Injection of LAK cells was continued once a week during hospitalization and once a month for outpatients. The duration of LAK therapy ranged from 3 to 23 months (mean 13.7 mos). Injections of LAK cells consisted of $0.5 \mathrm{ml}$ HBSS suspension injected into the Ommaya reservoir with a $26-\mathrm{G}$ needle and tuberculin syringe.

Patient response was usually evaluated at the end of radiotherapy by $\mathrm{CT}$ or $\mathrm{MR}$ imaging and neurological examination. However, the two patients who received LAK therapy alone were evaluated during the therapy. CT or MR imaging responses were graded as complete response (CR): disappearance of the tumor for at least 4 weeks, partial response (PR): a greater than $50 \%$ reduction in tumor size continuing for more than 1 week, no change (NC), and progressive disease (PD). The tumor size was measured using the greatest width and length. The neurological status was evaluated as 
Table 2 LAK therapy and evaluation

\begin{tabular}{|c|c|c|c|c|c|c|c|}
\hline \multirow{2}{*}{$\begin{array}{c}\text { Case } \\
\text { No. }\end{array}$} & \multicolumn{2}{|c|}{ LAK therapy } & \multirow{2}{*}{$\begin{array}{l}\text { Radiation } \\
\text { dose (Gy) }\end{array}$} & \multicolumn{3}{|c|}{ Evaluation } & \multirow{2}{*}{$\begin{array}{c}\text { Outcome } \\
\text { (survival time) }\end{array}$} \\
\hline & No, of injections & Total cell No. $\left(\times 10^{7}\right)$ & & $\mathrm{CT}$ and & MR imaging & KPS & \\
\hline 1 & 37 & 250 & 60 & & PR & 60 & died (16 mos) \\
\hline 2 & 39 & 370 & 61 & & PR & 90 & died (32 mos) \\
\hline 3 & 20 & 73 & - & & $\mathrm{NC}$ & 30 & died (22 mas) \\
\hline 4 & 15 & 65 & 54 & & $P D$ & 60 & died (10 mos) \\
\hline 5 & 31 & 90 & 60 & & $\mathrm{CR}$ & 90 & alive (90 mos) \\
\hline 6 & 23 & 87 & - & & PR & 60 & alive ( 24 mos) \\
\hline 7 & 17 & 44 & 65 & & $\mathrm{NC}$ & 90 & $\operatorname{died}(17$ mos $)$ \\
\hline 8 & 15 & 65 & 64.8 & & $\mathrm{CR}$ & 90 & alive $(24 \mathrm{mos})$ \\
\hline 9 & 23 & 87 & 64.8 & & $\mathrm{NC}$ & 90 & died (17 mos) \\
\hline 10 & 8 & 31 & 60 & & $\mathrm{NC}$ & 40 & alive $(12 \mathrm{mos})$ \\
\hline
\end{tabular}

improved, no change, and worse simultaneously with the CT or MR imaging evaluation. Figure 1 shows the treatment and evaluation scheme.

\section{Results}

LAK cells were administered to 10 patients on more than 200 occasions. No complications including headache, high fever, convulsion, infection, or bone marrow suppression were detectable in any patient. CT or MR imaging evaluation revealed that two of the 10 patients showed $C R$ after the radioimmunotherapy, three showed PR, four showed NC, and one showed PD (Table 2). The two patients (Cases 5 and 8) who showed CR both had astrocytoma grade III. Case 5 underwent subtotal removal of an astrocytoma grade II 4 years previously, and was readmitted because of multiple intraventricular tumors (Fig. 2), the diagnosis was based on neuroradiological findings only. Of the three patients with PR, one had a metastatic malignant melanoma
(Case 1, Fig. 3) and two had astrocytoma grade III (Cases 2 and 6). The four patients with $\mathrm{NC}$ had astrocytoma grade III or glioblastoma multiforme. Case 4 showed ventricular seeding of astrocytoma grade III following the combined radiation and LAK therapy and was evaluated as PD.

Neurological improvement was detected in one patient with pontine glioma (Case 6, Fig. 4). The level of consciousness improved with a marked decrease in intracranial pressure. The Karnofsky performance score of this patient reached 60 after 10 injections of LAK cells compared to 20 before starting the therapy. This patient was discharged 4 months after the initiation of LAK therapy. Other patients showed no neurological changes after the treatment. One patient (Case 1) contracted hydrocephalus, and subsequently received a ventriculoperitoneal shunt.

\section{Discussion}

The combined use of LAK therapy and irradiation to

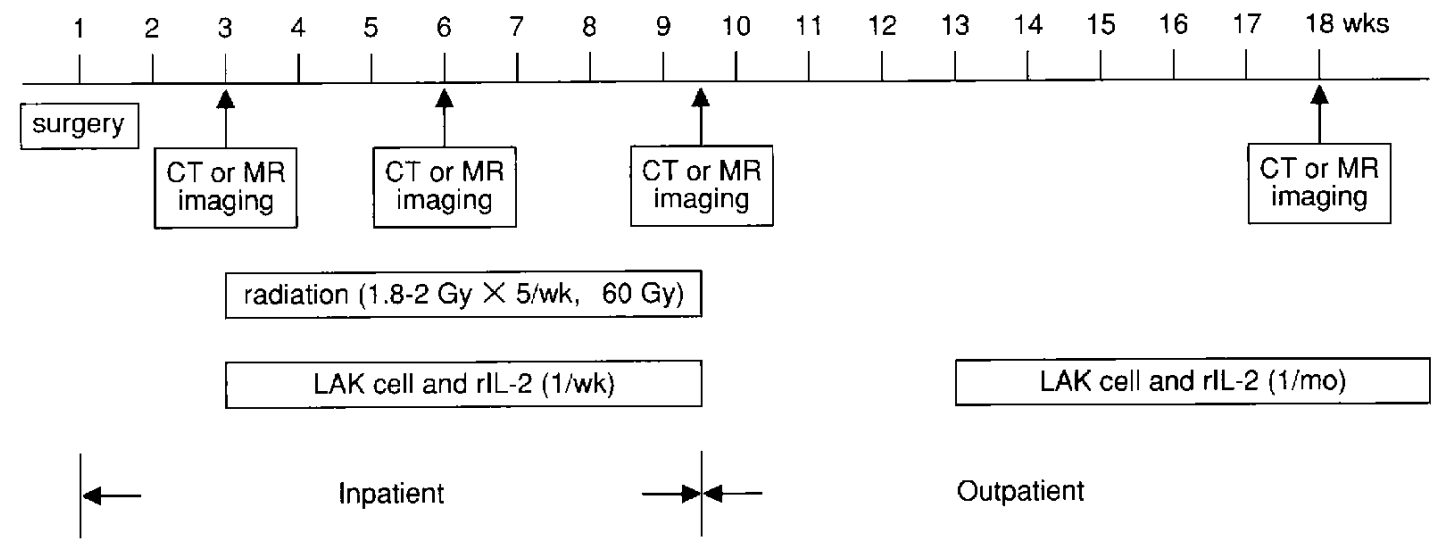

Fig. 1 Treatment and evaluation schedule. 

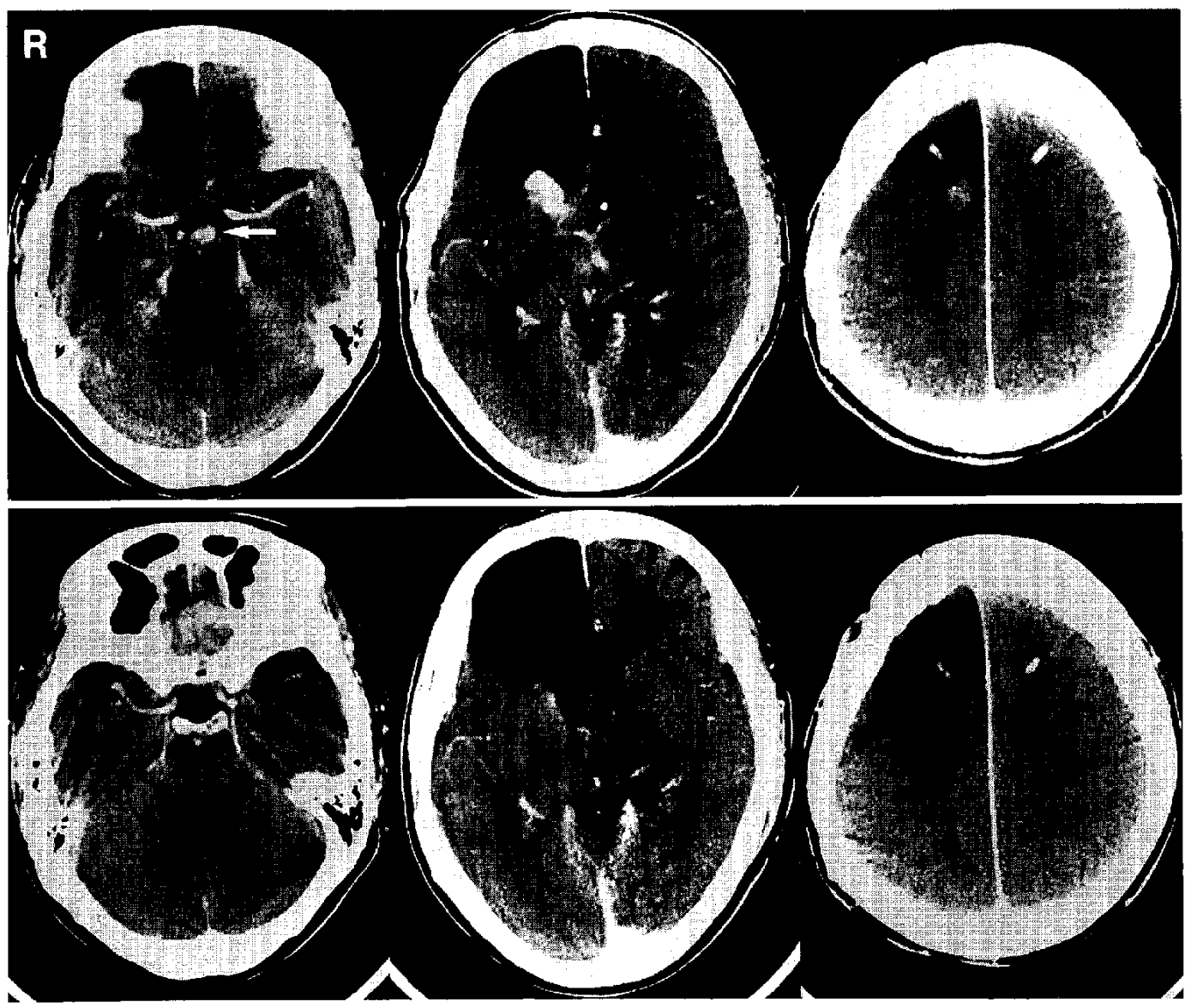

Fig. 2 Case 5. Postcontrast CT scans, demonstrating multiple enhanced masses in the third ventricle (arrow), lateral ventricle, and right high frontal lobe before treatment (upper), which disappeared 3 months after irradiation and LAK therapy (lower). This patient was evaluated as CR continuing for 24 months.

treat patients with malignant brain tumors achieved $\mathrm{CR}$ in two patients and $\mathrm{PR}$ in three. These results are more promising than in other studies using LAK cells, possibly because irradiation was used simultaneously with LAK therapy, and LAK therapy was continued for a relatively long period.

LAK cells were administered once a week during radiotherapy, as $95 \%$ of LAK cells injected into the tumor site survive for over 48 hours. ${ }^{10)}$ LAK cells injected into a surgical cavity combined with 4-6 Gy of irradiation per week should achieve enhanced cytotoxicity based on our previous experimental results. ${ }^{13,14)} \mathrm{NK}$ cells are more radioresistant ${ }^{13}$ and retain their lytic activity after 10 -Gy irradiation. ${ }^{8)}$ Our experimental data suggested that cytotoxic $\mathrm{T}$ cells did not lose their cytotoxic activity after 7.5-Gy irradiation (data not shown). Therefore, the lytic function of LAK cells should not be affected by 4- to 6-Gy irradiation.
Complications associated with administration of LAK cells seem to depend on the dose of IL-2 and the number of LAK cells. Previous trials have treated tumors using a large number of LAK cells. ${ }^{12}$ Barba et al. ${ }^{3)}$ reported cerebral edema and neurological deterioration in all patients using a relatively high dose of IL-2 and a much larger number of LAK cells administered locally. Merchant et al. ${ }^{11}$ reported headaches, low-grade fevers, and lethargy in all their patients with a high dose of IL-2 $\left(10^{6} \mathrm{U}\right)$ and local administration. Atkins et al. ${ }^{2)}$ reported hypothyroidism in $21 \%$ of patients treated by intravenous administration of IL- 2 and LAK cells. They suggested that the hypothyroidism might be caused by IL- 2 and LAK cells. In contrast, our study found no side effects. The low incidence of side effect might be due to injection of LAK cells and IL-2 into the local tumor cavity, the relatively small number of LAK cells used in each injection, and the low dose 


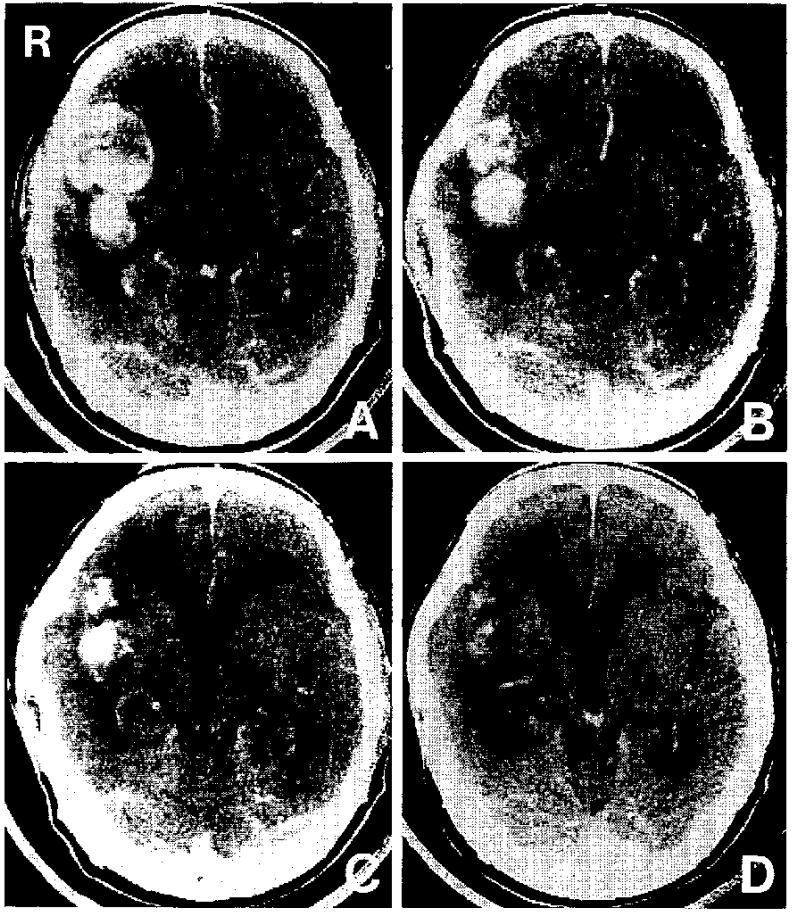

Fig. 3 Case 1. Postcontrast CT scans, showing metastatic malignant melanoma evaluated as PR 9 months after surgery. A: preoperative, B: 3 weeks postoperative, C: 3 months postoperative, D: 9 months postoperative.

of IL-2 $\left(1 \times 10^{4} \mathrm{U}\right)$. Our results suggest that a small number of LAK cells and a low dose of IL-2 are adequate without causing complications.

The outcome of LAK therapy is very difficult to predict. Our study included four patients without change (NC) and one with PD in addition to the five patients in whom the therapy was effective (CR and PR). The reasons for the different responses are still unknown. The number and frequency of LAK cell administration were the same for the two groups. The response may depend on the induction of suppressor cells among LAK cells.

No study has compared the in vitro LAK cell activity and the clinical effect. However, Merchant et al. ${ }^{11}$ tested LAK cell activity using a NK-resistant Daudi cell line and evaluated the clinical course of these patients. The results seemed to show no significant correlation between clinical response and non-response. Our study included three astrocytoma grade III patients with relatively short survival times (Cases 4,7 , and 9). In Case 4, the tumor spread to the ventricular system from the beginning of treatment although the primary tumor appeared to shrink. Case 9 also showed ventricular seeding 4 months after the completion of treatment. In this patient, the retinoblastoma (RB) gene was thought to be rearranged or point mutated (data not shown). The RB gene is thought to be one of the tumor suppressor genes. ${ }^{5)}$ Further investigation of tumor suppressor genes or oncogenes may allow prediction of tumor growth or the mechanism of tumor progression.

Low-dose LAK therapy, with or without radiation therapy, is potentially an effective and safe procedure for the treatment of patients with malignant brain tumor, but further clinical trials are necessary to obtain significant data.

\section{References}

1) Anderson RE, Warner NL: Ionizing radiation and immune response. $A d v$ Immunol 24: 215-335, 1976

2) Atkins MB, Mier JW, Parkinson DR, Gould JA, Berkman EM, Kaplan MM: Hypothyroidism after treatment with interleukin-2 and lymphokine activated killer cells. $N$ Engl $J$ Med 318: 1557-1563, 1988

3) Barba D, Saris SC, Holder C, Rosenberg SA, Oldfield E: Intratumoral LAK cell and interleukin-2 therapy of human gliomas. $J$ Neurosurg 70 : 175-182, 1989

4) Bosnes V, Hirschberg $\mathrm{H}$ : Comparison of in vitro glioma cell cytotoxicity of LAK cells from glioma patients and healthy subjects. $J$ Neurosurg 69: 234-238, 1988

5) Friend SH, Bernards R, Rogelj S, Weinberg RA, Rapaort JM, Albert DM, Dryja TP: A human DNA segment with properties of the gene that predisposes to retinoblastoma and osteosarcoma. Nature 323: 643-646, 1986

6) Grimm EA, Mazumder A, Zhang HZ, Rosenberg SA: Lymphokine-activated killer cell phenomenon. Lysis of natural killer resistant fresh solid tumor cells by interleukin 2-activated autologous human peripheral blood lymphocytes. J Exp Med 155: 1823 1841,1982

7) Henkart PA, Yue CC, Yang J, Rosenberg SA: Cytolytic and biochemical properties of cytoplasmic granules of murine lymphokine-activated killer cells. J Immunol 137: 2611-2617, 1986

8) Hochman PS, Cudkowicz G, Dausset J: Decline of natural killer activity in sublethaly irradiated mice. $J$ Natl Cancer Inst 61: 265-268, 1978

9) Jacobs SK, Melin G, Holcomb B, Parham CW, Kornblith PL, Grimm EA: Lymphokine activated killer (LAK) cell-mediated lysis of murine glioma: Trypsin-chemotrypsin-sensitive glioma protein is responsible for tumor-specific recognition by LAK cells. Brain Res 372: 386-389, 1986

10) Jacobs SK, Wilson DJ, Kornblith PL, Grimm EA: Interleukin-2 or autologous lymphokine-activated killer cell treatment of malignant glioma: Phase 1 trial. Cancer Res 46: 2101-2104, 1986

Neurol Med Chir (Tokyo) 35, January,

1995 

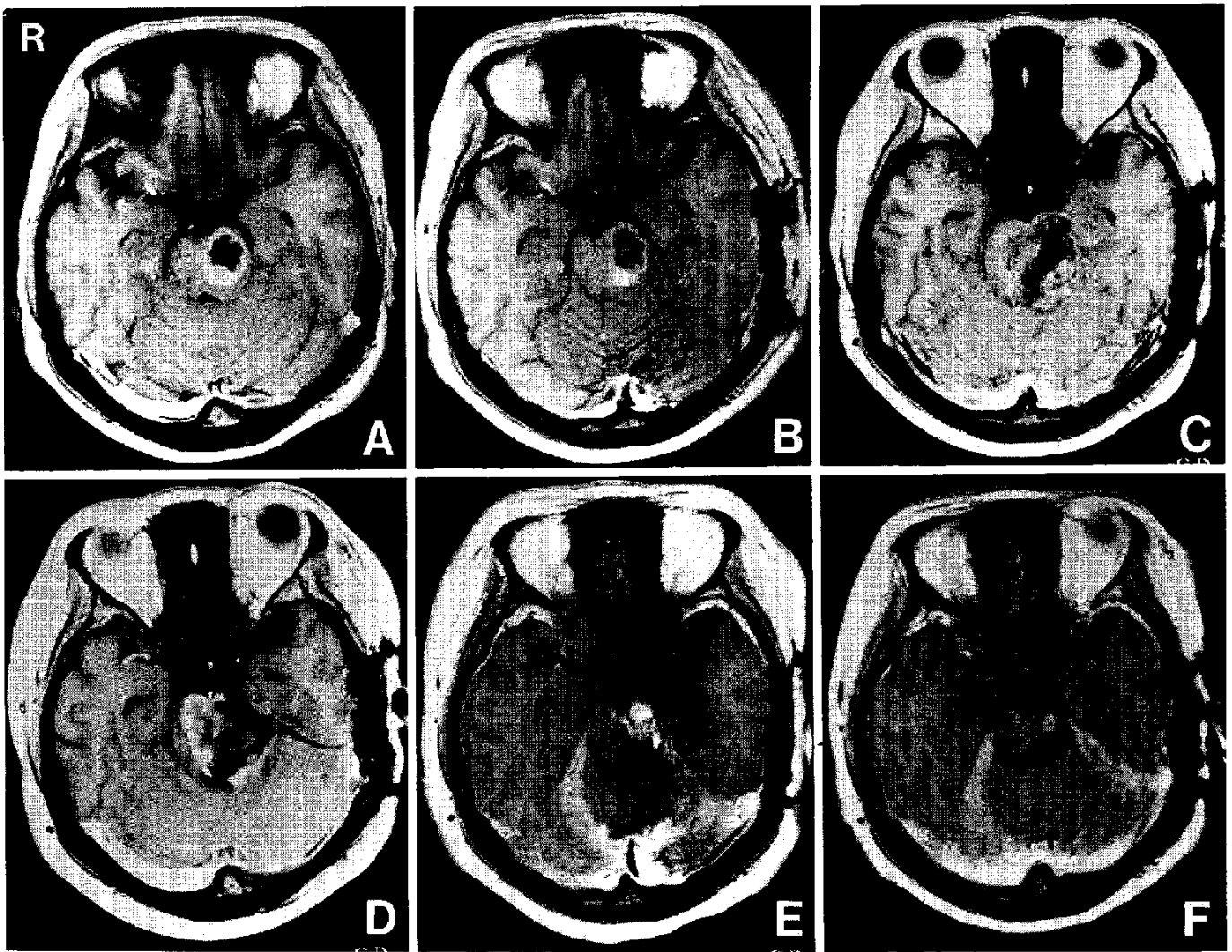

Fig. 4 Case 6. Serial $\mathrm{T}_{1}$-weighted $\mathrm{MR}$ images with gadolinium-diethylenetriaminepenta-acetic acid, showing marked regrowth of pontine glioma despite radiotherapy and chemotherapy 3 months after surgery. Administration of LAK cells and ILL-2 was started 5 months after the surgery. The huge pontine glioma gradually decreased in size and was evaluated as PR. A: preoperative, B: postoperative, $\mathrm{C}: 3$ months postoperative, $\mathrm{D}: 5$ months postoperative, $\mathrm{E}: 11$ months postoperative, F: 15 months postoperative.

11) Merchant RE, Merchant LH, Cook SHS, McVicar DW, Young HF: Intralesional infusion of lymphokine-activated killer (LAK) cells and recombinant interleukin-2 (rIL-2) for the treatment of patients with malignant brain tumor. Neurosurgery 23: 725732,1988

12) Muul LM, Director EP, Hyatt CL, Rosenberg SA: Large scale production of human lymphokine activated killer cells for use in adoptive immunotherapy. J Immunol Methods 88: 265-275, 1986

13) Nakagawa $K$, Omori $N$, Hashimoto $K$, Yamamoto $T$, Nose T: The combined effect of lymphokine activated killer cell and radiation therapy on rat brain tumor in vitro. Biotherapy 4: 109-115, 1992

14) Nakagawa $K$, Yoshida $F$, Omori $N$, Tsunoda $T$, Nose $T$ : The effect of radiation therapy combined with natural killer cells against spontaneous murine fibrosarcoma. Biotherapy 2: 69-75, 1990

15) Nitta $T$, Sato K, Yagita H, Okumura K, Ishii S: Preliminary trial of specific targeting therapy against malignant glioma. Lancet 335: 368-371, 1990
16) Tzeng J-J, Barth RF, Clendenon NR, Gordon WA: Adoptive immunotherapy of a rat glioma using lymphokine-activated killer cells and interleukin 2 . Cancer Res 50: 4338-4343, 1990

17) Vaquero J, Martinez R, Ramiro J, Salazar G, Barbolla $\mathrm{C}$ : Immunotherapy of glioblastoma with intratumoral administration of autologous lymphocytes and human lymphoblastoid interferon. A further clinical study. Acta Neurochir (Wien) 109: $42-45,1991$

18) Yoshida S, Tanaka R, Takai K, Ono K: Adoptive immunotherapy with LAK cells and interleukin-2 in the treatment of recurrent malignant gliomas. Current Therapeutic Research 47: 654-666, 1990

Address reprint requests to: K. Nakagawa, M.D., Department of Neurological Surgery, Institute of Clinical Medicine, University of Tsukuba, 1-1-1 Tennodai, Tsukuba, Ibaraki 305, Japan. 